\title{
Effect of residual elements on high performance nickel base superalloys for gas turbines and strategies for manufacture
}

\author{
O P SINHA*, M CHATTERJEE, V V R S SARMA and S N JHA \\ Mishra Dhatu Nigam Limited, P.O. Kanchanbagh, Hyderabad 500 058, India
}

\begin{abstract}
The need for better gas turbine operating efficiency and reliability has resulted in tightening of specification and acceptance standards. It has been realized that some elements even at trace level, can have disastrous effect on high temperature properties. The present paper highlights the adverse effect of tramp elements and strategies that should be adopted to produce high purity superalloys.
\end{abstract}

Keywords. Superalloys; tramp elements; creep and stress rupture properties; vacuum induction melting.

\section{Introduction}

Nickel base superalloys, by virtue of their excellent high temperature properties coupled with corrosion resistance, have been widely used as gas turbine engine components. The physical metallurgy of superalloys demands the highest degree of process consistency and reproducibility, requiring melters of these alloys to exercise strict control and discipline during manufacture. The need for improved gas turbine operating efficiency and reliability has resulted in extremely stringent acceptance criteria. Gases, particularly oxygen and nitrogen, are required to be controlled to $<10 \mathrm{ppm}$, while several tramp elements which are considered deleterious, needs to be controlled to $<1 \mathrm{ppm}$. These restrictions are a big challenge to metallurgists and suitable strategies should be evolved from basic thermodynamic considerations in order to get desired results. The paper highlights the effect of impurities on the performance of superalloys and strategies that should be adopted during processing.

\section{Effect of trace elements}

Elements which are present in superalloys in parts per million (ppm) level are generally known as trace elements. While most of them are undesirable, some elements, especially $\mathrm{Mg}, \mathrm{B}, \mathrm{Zr}, \mathrm{Y}$, Ce etc are sometimes deliberately added in controlled amounts to enhance the hot workability or high temperature performance.

Figure 1 shows the periodic grouping of deleterious trace elements for remelt bar superalloys (Durber and Boneham 1984). All the elements have a measurable negative effect upon the mechanical properties of superalloys even when they are present in ppm level. The prime concern of elements are metals and metalloids of groups I-VI such as $\mathrm{Ag}, \mathrm{Pb}, \mathrm{Bi}, \mathrm{Tl}, \mathrm{Te}, \mathrm{As}, \mathrm{Sn}, \mathrm{Sb}$ etc.

*Author for correspondence (hyd1_spralloy@ sancharnet.in)
The tramp elements are known to migrate to grain boundaries and drastically reduce the ductility, creep and stress rupture properties by grain boundary decohesion. Figures 2 and 3 show the effect of some of the impurities on rupture life of IN100 and MAR M002 alloys, respectively (Ford 1984). In terms of severity, $\mathrm{Bi}$ is by far the most damaging element, followed by $\mathrm{Te}, \mathrm{Se}, \mathrm{Pb}$ while elements like $\mathrm{Ag}$ and $\mathrm{Sn}$ seems to have very little effect. $\mathrm{Bi}$ even at a level of $0.2 \mathrm{ppm}$ has been found to reduce the creep ductility of cast superalloys by atleast $20 \%$.

It has been shown that severe micro-porosity can occur during solidification in nickel base alloys containing high concentration of nitrogen (Bieber and Decker 1961). This results in reduced creep properties in intermediate temperature ranges. Nitrogen also results in formation of very stable nitrides such as $\mathrm{Ti}, \mathrm{Hf}$, etc which act as nuclei for the growth of MC type carbides. They also act as grain nucleation sites, giving rise to equiaxed grains in directionally solidified castings (figure 4) (Meetham 1984). Similarly, it has been shown that stress rupture lives of cast and powder fabricated superalloys are very sensitive to trace amount of oxygen as shown in figure 5 (Gessinger and Bomford 1974). Elements such as $\mathrm{Pb}, \mathrm{Bi}$ etc have adverse effect on hot workability of superalloys by forming low melting compounds at grain boundaries. As seen from figure 6 (Heslop and Knott 1971), even at about $10 \mathrm{ppm}$ level, lead was found to reduce the hot ductility of Nimonic 105 to about two thirds of the alloy which was lead free. Residual non-metals such as sulphur has similar negative effect on hot workability by accumulation at grain boundaries. The adverse effect of sulphur on hot workability can be controlled through careful additions of minor elements such as $\mathrm{Mg}, \mathrm{Ca}, \mathrm{Zr}$, $\mathrm{Ce}, \mathrm{Y}$ etc. These elements are added in controlled amounts to combine with sulphur and render it innocuous. A small amount of these elements is also known to preferentially migrate to energy lowering sites such as grain boundary and prevent dislocation pile up and brittle behaviour. Excessive addition, however, can result in drastic reduction of 
hot ductility by formation of low melting compounds at grain boundary (figure 7) (Betteridge and Heslop 1974).

\section{Vacuum induction melting and quality enhancement}

Great advancements in vacuum melting and casting technologies as well as analytical capabilities, have provided the impetus to develop high purity advanced superalloys for aero engines in a commercial scale. Vacuum induction melting (VIM) provides the platform to carry out degassing, removal of volatile impurities through distillation and accurate chemistry control, even for highly reactive and oxidizable elements such as Ti, Hf, Y etc.

Oxygen can be conveniently removed through initiation of carbon-oxygen reaction and the progress of the reaction can be monitored continuously with the help of an on line mass spectrometer and checking the hot leak rate. Proper choice of crucible refractory lining, effective stirring and purging as well as good control over vacuum

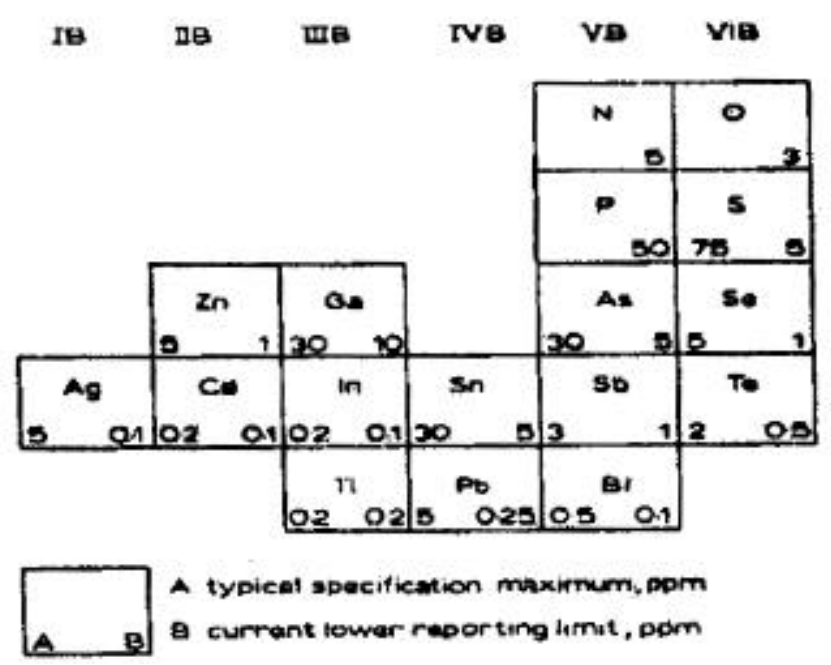

Figure 1. Periodic grouping of deleterious trace elements in superalloys (after Durber and Boneham 1984).

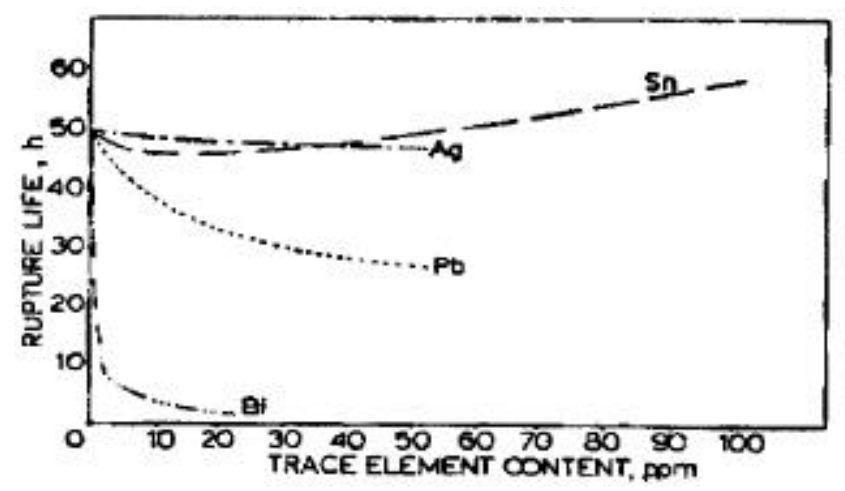

Figure 2. Variation of stress rupture life with impurities, IN 100 alloy (after Ford 1984). are the key factors for achieving low oxygen level in the product.

Nitrogen removal is of critical importance in superalloy melting, because the alloy invariably contains strong nitride forming elements. In the absence of strong nitride formers, one can expect rapid removal of nitrogen especially during carbon boil. Longer holding times as well as purging could be used to achieve lower nitrogen, but can result in melt contamination due to refractory wear. Nitrogen desorption from the melt is also related to the presence of surface active elements such as sulphur and oxygen. Lowering of both these elements helps better desorption of nitrogen from the melt.

Since slag-metal reactions are not feasible under vacuum induction melting conditions, significant sulphur removal cannot be achieved during processing. As mentioned earlier, addition of $\mathrm{Mg}, \mathrm{Ca}, \mathrm{Ce}$ etc is carried out towards the end of melt in order to desulphurize the bath. Otherwise, 'sulphur' is mainly controlled through judicious selection of raw materials or their purification prior to vacuum melting.

Figure 8 shows the removal of metalloid trace elements during vacuum melting (Turillon 1963). While elements like $\mathrm{Bi}, \mathrm{Pb}, \mathrm{Se}$, Te are significantly removed by distillation, elements like As, Sn, Sb are not affected. Three dis-

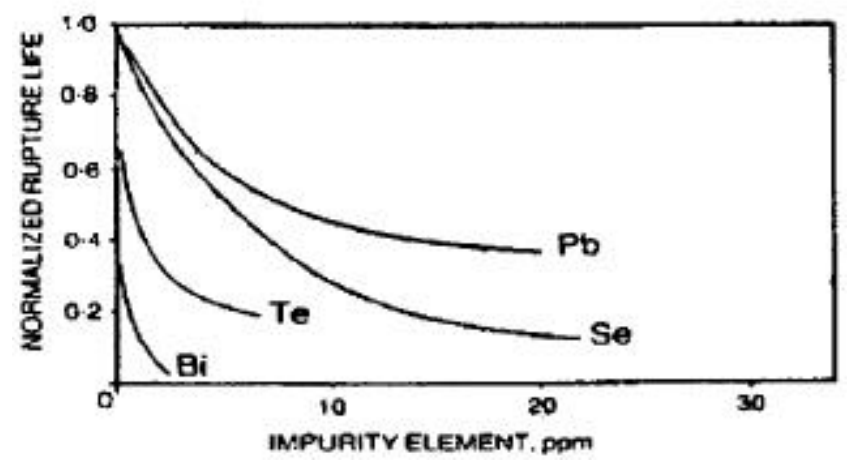

Figure 3. Effects of metalloids on rupture life of MAR M 002 alloy (after Ford 1984).

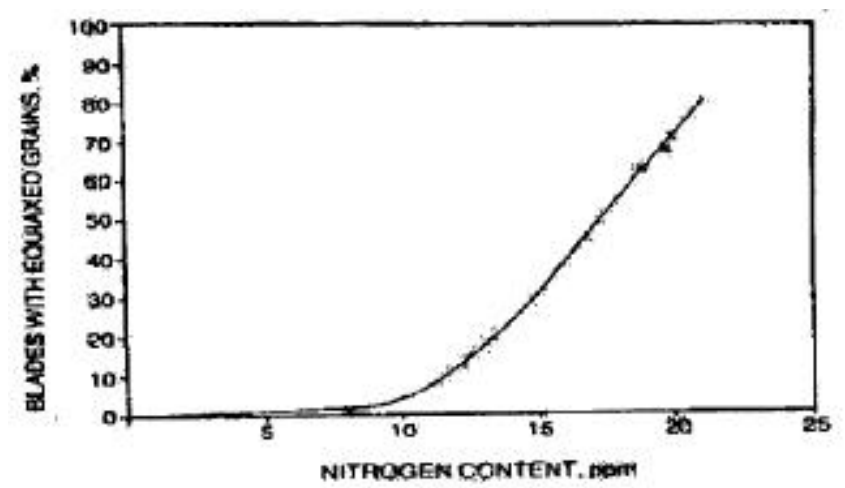

Figure 4. Effect of nitrogen on grain structure of directionally solidified MAR-M 246 castings (Meetham 1984). 
tinct areas, such as diffusion in melt, evaporation at melt surface, and vapour transport and condensation, can be identified as possible rate controlling steps. Effective stirring can be used to minimize concentration gradient near the melt surface and enhance removal by volatilization. The evaporation rate can also be increased by lowering the pressure above the melt or super heating the melt. The latter method should not be encouraged since it leads to increase in the reaction with crucible lining material.

\section{Strategies for production of high purity superalloys}

Achieving extremely low oxygen, sulphur and nitrogen $(<10 \mathrm{ppm})$ as well as controlling the tramp elements to extreme low levels ( $<1$ to $10 \mathrm{ppm}$ ) is indeed a formida-

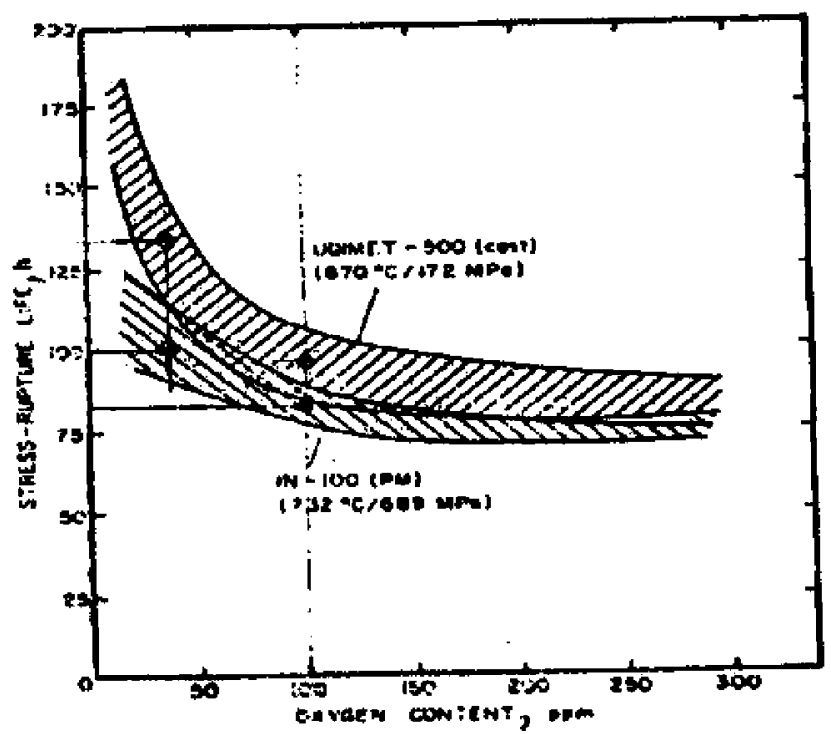

Figure 5. Effect of oxygen on stress rupture life of cast Udimet 500 and PM IN-100 (after Gessinger et al 1974).

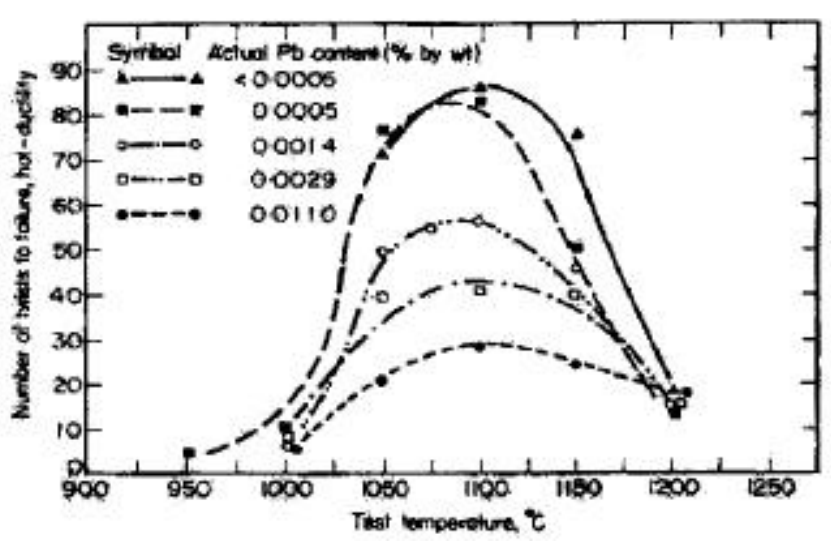

Figure 6. Effect of lead contents on the high-temperature ductility of Nimonic 105 (after Heslop and Knott 1971). ble task. Control of nitrogen is particularly challenging for superalloys containing significant quantities of strong nitride forming elements such as $\mathrm{Ti}, \mathrm{Hf}, \mathrm{Ta}, \mathrm{Al}$ etc. Some of the elements, especially $\mathrm{Ti}, \mathrm{Hf}, \mathrm{Al}$ etc are highly oxidizable and are added towards the end of the melting cycle. Nitrides of these elements are not dissociated and tend to remain suspended in the melt as fine particles. Zirconia based refractory foam filters are generally ineffective in removing these particles by trapping. Therefore, it is very important to identify suitable sources of these raw materials that contain very low nitrogen. Otherwise, commercially available raw materials have to be subjected to multiple refining using vacuum arc remelting (VAR) or electron beam cold hearth remelting (EBCHR) processes to achieve the desired results, prior to their use. Because of its abundance in nature, sulphur in natural raw material tends to be high. Since significant desul-

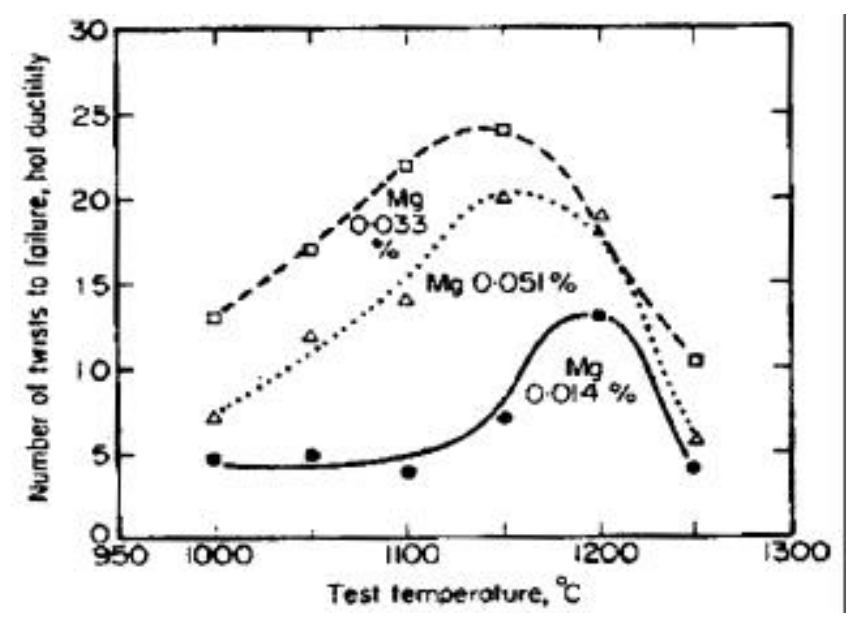

Figure 7. Effect of magnesium on hot workability of Nimonic PE13 (after Betteridge and Heslop 1974).

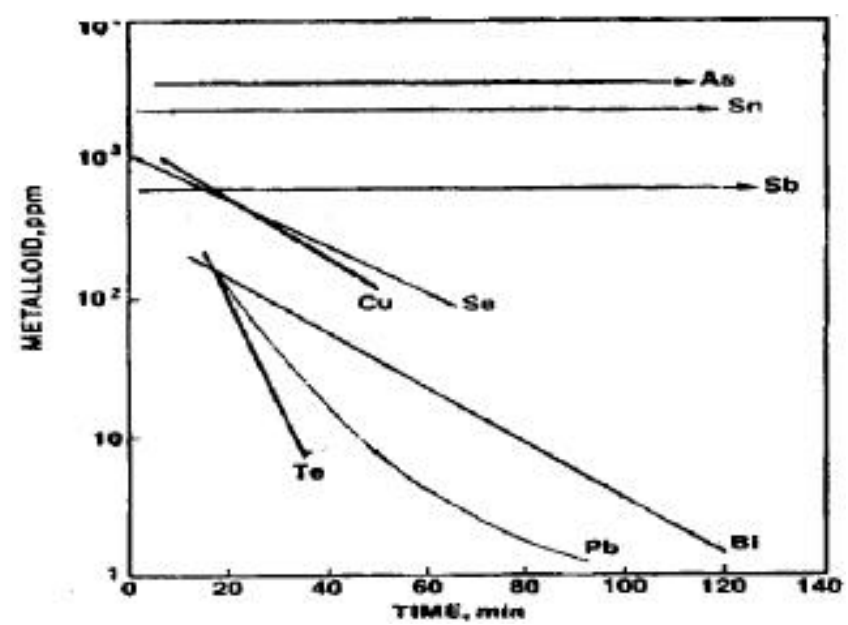

Figure 8. Removal rates of metalloids during vacuum melting of $80 \mathrm{Ni}-20 \mathrm{Cr}$ (after Turillon 1963). 
phurization during vacuum melting is not practicable, the virgin raw materials should be externally refined through slag-metal reaction using suitable lime based flux. Tramp elements which are not removable by distillation, should be controlled by careful selection of raw materials. Detailed analysis of all impurities using advanced analytical techniques such as inductively coupled plasma spectrometer (ICPS), inductively coupled plasma mass spectrometer (ICPMS) and glow discharge mass spectrometer (GDMS), coupled with proper raw material mass balancing prior to melt should be carried out to identify the contribution of impurities from different alloying additions. Lastly, it is also important to optimize melt related parameters such as stirring rate, purging rate and duration, tundish design and type of filter etc in order to produce premium quality superalloys.

\section{Conclusions}

(I) Selection of virgin metals and master alloys with low impurity levels should be in line with the acceptance limit in product.

(II) Raw materials having high S, P, N levels, should be subjected to external purification by slag-metal reaction and vacuum melting.

(III) Reactive elements such as Ti, Hf, Al etc should be added towards the end of the melt preferably as master alloys to prevent undesirable reaction with refractory lining and achieve better recoveries during melting.

(IV) Beneficial trace elements like $\mathrm{Mg}, \mathrm{Zr}, \mathrm{Ce}, \mathrm{Y}$ etc are most effective when optimum quantity is used during melting process.

\section{Acknowledgements}

The authors would like to express their gratitude and sincere appreciation to Chairman \& Managing Director for his encouragement.

\section{References}

Betteridge W and Heslop J 1974 The Nimonic alloys hot working (London: Edward Arnold) 2nd ed. pp 129-149

Bieber C G and Decker R F 1961 Trans. AIME 221629

Durber G L R and Boneham M 1984 Metals Technol. 11428

Ford D A 1984 Metals Technol. 11438

Gessinger G H and Bomford M 1974 J. Int. Metall. Rev. 1951

Heslop J and Knott A R 1971 Metals \& Mater. 559

Meetham G W 1984 Metals Technol. 11414

Turillon P P 1963 in Transaction of the 6th international vacuum metallurgy conference (ed.) R F Bunshah (Boston: American Vacuum Society) pp 88-102 